\title{
The formulation and development of methods of solving thermomechanics problems for irradiated layered solids
}

\author{
Hachkevych O., Terlets'kyi R., Turii O. \\ Pidstryhach Institute for Applied Problems of Mechanics and Mathematics \\ National Academy of Sciences of Ukraine \\ 3-b Naukova Str., Lviv, 79060, Ukraine
}

(Received 5 June 2017)

\begin{abstract}
A mathematical model to describe a thermoelastic state of plane-parallel plates (plate composites) subjected to a thermal radiation is developed. The model is grounded on phenomenological theory of radiation and quasistatic thermoelasticity. It takes into account an effect of radiation on plate surfaces, contact boundaries, and in semi-transparent areas. It is assumed a perfect contact between the constituents of layers that boundary contact is modeled on the plane surface defined on both sides of its radiation characteristics of the material layers and the conditions of heat and mechanical contacts are ideal. The methods to solve new nonlinear contact-boundaries problems of thermoelasticity are proposed. On analysing the posed problems solutions, the new features of temperature and stresses distributions in plates are established, dependent on radiative properties of layers, layer's thickness and on source temperature.
\end{abstract}

Keywords: modeling, thermal and stressed states, thermal irradiation, heat transfer, multilayered plates, semi-transparent and opaque layers.

2000 MSC: $74 \mathrm{~A} 15,74 \mathrm{G} 15$

UDC: 539.3

\section{Introduction}

Modern technologies of thermal treatment metallic and non-metallic materials widely use thermal radiation due to the possibility of uniform field intensity in a defined part or the whole surface of the sample and the simplicity of the implementation. Very often elements of constructions and devices especially in aerospace and aeronautical engineering, nuclear and chemical power engineering are subjected to thermal irradiation or high temperatures when operating.

Impact of heat radiation (includes the spectral region from the ultraviolet to the far infrared (the wavelengths $0.4 \div 1000 \mu \mathrm{m})$ ) on the solid made from different materials is determined by their transparency. Opacity (full absorption of radiation energy in a very thin surface layer, the order $100-1000$ of angstroms) is characteristic of metal, whereas partial transparency (absorption by the thickness of a micrometer to several meters) characteristic of non-metallic. It is determined by the peculiarities of the propagation and absorption of both the external thermal radiation, and radiation in the body of its own, since the heated body itself is a source of radiation.

The absorption and emission of thermal energy by solids depending on their transparency has a surface or volume character and affects the course of interrelated thermal and mechanical processes in such solids. Given this, the statement of boundary problems of heat transfer and thermoelasticity considering radiation heat transfer is a relevant and important (in particular for the destination irradiation) for solids of various transparency and development methods for investigation of thermal stress state in order to: predicting thermomechanical behavior of structural elements and devices, that exploited under conditions of thermal irradiation or high temperatures; the development of theoretical foundations for the creation of new and improvement of existing technologies and regimes of thermal treatment of products using thermal radiation. 
Necessity of investigation the thermomechanical behavior of solids under the action of light electromagnetic radiation (includes the infrared radiation (frequencies $3 \cdot 10^{11}-3 \cdot 10^{14} \mathrm{~Hz}$ ), visible light $\left(3 \cdot 10^{14}-3 \cdot 10^{15} \mathrm{~Hz}\right)$ and ultraviolet radiation $\left.\left(3 \cdot 10^{15}-3 \cdot 10^{17} \mathrm{~Hz}\right)\right)$, as a thermal and non-thermal (laser) has led to the formulation of a new class of problems - problems of radiation thermomechanics. Although the heat radiation has electromagnetic nature, the use for modeling thermo mechanics of deformable solids under conditions of thermal radiation of theories of interaction, based on the classical theory of the electromagnetic field is associated with significant difficulties. They appear as the description of electromagnetic properties materials, and in the investigation of the propagation of radiation such wavelength in the medium [1]. Therefore, in the literature to investigate the propagation of thermal electromagnetic radiation and modeling of its effect on the thermomechanical processes in the solids is used the phenomenological theory of radiation, based on Planck's and Bugera's laws (electrodynamic theory is more complicated) [2-6]. On its basis, the theory of heat radiation in a continuous medium is developed $[4,5]$, which explores the thermal state of solids of different transparency, taking into account the absorption and emission of thermal radiation energy. At the same time, for opaque solids, these processes are considered superficial and were taken into consideration in the balance of heat flux on the surface of the body (the formulation of the thermal boundary conditions). In the semi-transparent (partial transparent) solids the propagation of radiation is described by the transfer equation, and its absorption and emission is associated with volumetric heat emission, which, as a heat source, take into account in the heat conduction equation. A sufficiently complete review of studies of heat transfer in semi-transparent and opaque solids, taking into account the peculiarities of the emergence and propagation of thermal radiation in them made in [7-9].

In the radiation heat transfer theory in a continuous medium are known investigations in conjunction of radiation and heat (radiation-conductive heat transfer) in layered semi-transparent solids that carried out primarily for two-layer plates [10-16]. The proposed models are based on a phenomenological theory of radiation semi-transparent solids, were taken into account the effects of emission and absorption of thermal energy in the layers, the reflection and refraction of radiation at the interface, modeled by flat physical surface with predetermined reflective characteristics on both its sides.

It is considered that such layered flat system is between opaque surfaces with predetermined radiation (emitting and reflecting) properties and temperature and at the interface between layers the conditions ideal thermal contact (equality of temperatures and heat fluxes due to heat conduction) are satisfied. However, in the literature on heat exchange by radiation the propagation of radiation and heat transfer in layered solids with components of different transparency have not studied. With the use of methods radiation heat transfer theory in a continuous medium are proposed variants of thermomechanics of homogeneous opaque solids under conditions of (convective-radiative) heat exchange [17-19] and semi-transparent by the thermal irradiation [20-23]. On their basis are formulated and produced a number of concrete problems for investigation of thermomechanical behavior of solids (in particular, temperature-sensitive, with impurities) of varying transparency, taking into account the effect of thermal radiation [17-22,24-29] and others. Apart from the mentioned works, some of the problem of thermoelastic state of semi-transparent solids under the impact of thermal radiation were considered in [30,31], and opaque - in [32].

As part of the radiation thermomechanics not investigated thermostressed state irradiared as semitransparent layered solids, and solids with components of different transparency.

The article is devoted to the development of methods for studying thermal stress state of the irradiated plane-layered bodies (plates) and to identify patterns of their thermomechanical behavior depending on the radiative properties of the component layers, their thickness and the radiation source temperature. 


\section{Formulation of problems of thermomechanics for irradiated two-layered plates}

In this paper we considered the peculiarities of radiative thermomechanics problems definitions for irradiated layered solids using example two-layered plane-parallel solids (plates) with components of different transparency. We assume that there is a perfect contact between the layers in which border of contact is modeled on a plane surface defined on both sides of its radiation characteristics of the material layers and thermal conditions and mechanical contact - ideal. Therefore, we consider components plates which are opaque or semi-transparent solids throughout the range of the spectrum of thermal radiation

In the study of the thermal state of different transparent solids caused by heat radiation, external thermal radiation from the heated body may be set approximately in the environment (which is considered transparent) by spectral intensity $I_{\lambda s}\left(\boldsymbol{x}, t, \boldsymbol{g}_{0}\right)(\lambda$ is wavelength) falling radiation on body from the real source. This intensity on the body surface is a function of the point (characterized by the radius-vector $\boldsymbol{x})$, the time $t$ and the direction $\left(\boldsymbol{g}_{0}\right.$ is unit vector in the direction of the ray). It can be accepted proportional to the spectral intensity blackbody radiation at the temperature $T_{s}$ source, i.e. $I_{\lambda s}\left(\boldsymbol{x}, t, \boldsymbol{g}_{0}\right)=k_{\lambda}\left(\boldsymbol{x}, \boldsymbol{g}_{0}\right) I_{b \lambda}\left(\lambda, T_{s}\right)$, where $k_{\lambda}\left(\boldsymbol{x}, \boldsymbol{g}_{0}\right)$ is defined function, which look set depending on the energy and spectral characteristics of the real source of radiation and its location relative to the body. This ratio we use when setting field of irradiation on the surface of a two-layer plate.

Propagation of heat radiation in a semi-transparent layer of the plate describe quasi-stationary transfer equation $[33,34]$ relatively spectral radiation intensity $I_{\lambda s}\left(\boldsymbol{x}, t, \boldsymbol{g}_{0}\right)$, which determines the radiation attenuation $\left(a_{\lambda}\right.$ is spectral absorption coefficient) in the direction of the ray and also takes into account their emission radiation (directly emitted radiation) $I_{m \lambda}=\left(n_{\lambda}\right)^{2} I_{b \lambda}[T(\boldsymbol{x}, t)](T(\boldsymbol{x}, t)$ is the temperature in the layer, $n_{\lambda}$ is refractive index). Its solution is presented in the form [4],

$$
I_{\lambda}\left(\theta_{\lambda}, t, \boldsymbol{g}_{0}\right)=I_{\lambda}^{e f}\left(\boldsymbol{x}, t, \boldsymbol{g}_{0}\right) \exp \left(-\theta_{\lambda}\right)+\int_{0}^{\theta_{\lambda}} I_{m \lambda}^{*}(\lambda, T) \exp \left[-\left(\theta_{\lambda}-\theta_{\lambda}^{*}\right)\right] d \theta_{\lambda}^{*},
$$

where $\theta_{\lambda}(\boldsymbol{x})=\int_{0}^{g\left(x_{i}\right)} a_{\lambda}\left(g^{*}\right) d g^{*}$ is the optical thikness in the layer ( $x_{i}$ are Cartesian coordinates); $I_{\lambda}^{e f}$ is effective intensity radiation, which departs from the interface of the opaque layer or from the border of the plate at the point $\boldsymbol{x}$ in the direction $\boldsymbol{g}_{0}$ into the layer. Effective intensities on borders of semitransparent layer is found using boundary conditions which express the balance of fluxes of radiation which summarizes to the border (including a couple of reflections inside layer). These conditions are a system of two Fredholm integral equations of the second order. In general, each of the equations can be written as

$$
I_{\lambda}^{e f}\left(\boldsymbol{x}, t, \boldsymbol{g}_{0}\right)=I_{\lambda}^{r f}\left(\boldsymbol{x}, t, \boldsymbol{g}_{0}\right) \frac{1}{\pi} \int_{\Gamma} R_{\lambda}^{\prime \prime}\left(\boldsymbol{x}, \boldsymbol{g}_{0}, \boldsymbol{g}_{0}^{\prime}\right) I_{\lambda}^{i n c}\left(\boldsymbol{x}, t, \boldsymbol{g}_{0}^{\prime}\right) \cos \left(\boldsymbol{g}_{0}^{\prime} \wedge \boldsymbol{n}\right) d \Gamma_{\boldsymbol{g}_{0}^{\prime}}
$$

Here $I_{\lambda}^{r f}$ is the spectral intensity of radiation refracted from the environment or emited from the surface contacting opaque layer; $I_{\lambda}^{\text {inc }}\left(\boldsymbol{x}, t, \boldsymbol{g}_{0}^{\prime}\right)$ is the intensity of the radiation falling on border from the inside of the layer in the direction $\boldsymbol{g}_{0}^{\prime} ; R_{\lambda}^{\prime \prime}\left(\boldsymbol{x}, \boldsymbol{g}_{0}, \boldsymbol{g}_{0}^{\prime}\right)$ is bidirectional reflectance spectral ability of the border, and $\boldsymbol{n}$ is a vector of normal to it. Integration is carried out by solid angle $=2 \pi\left(d_{\boldsymbol{g}_{0}^{\prime}}\right.$ is its element in the direction $\left.\boldsymbol{g}_{0}^{\prime}\right)$. If, semi-transparent layer borders on the transparent environment $\left(n_{\lambda} \approx 1\right)$, then $I_{\lambda}^{r f}\left(\boldsymbol{x}, t, \boldsymbol{g}_{0}^{\prime}\right)=n_{\lambda}^{2}\left[1-R_{\lambda}^{\prime}\left(\boldsymbol{x}, \boldsymbol{g}_{0}^{\prime \prime}\right)\right] I_{\lambda s}\left(\boldsymbol{x}, t, \boldsymbol{g}_{0}^{\prime \prime}\right)$, where $R_{\lambda}^{\prime}\left(\boldsymbol{x}, \boldsymbol{g}_{0}^{\prime \prime}\right)$ is unidirectional reflective ability border. Directions $\boldsymbol{g}_{0}$ and $\boldsymbol{g}_{0}^{\prime \prime}$ are related by ratio $\sin \left(\boldsymbol{g}_{0} \wedge \boldsymbol{n}\right) / \sin \left(\boldsymbol{g}_{0}^{\prime \prime} \wedge \boldsymbol{n}\right)=n_{\lambda}$. On the boundary of contact with the opaque layer $I_{\lambda}^{r f}\left(\boldsymbol{x}, t, \boldsymbol{g}_{0}^{\prime}\right)=I_{\lambda}^{o p}\left(\boldsymbol{x}, t, \boldsymbol{g}_{0}^{\prime}\right)$, where $I_{\lambda}^{o p}\left(\boldsymbol{x}, t, \boldsymbol{g}_{0}^{\prime}\right)=\varepsilon_{\lambda}^{\prime}\left(\boldsymbol{x}, \boldsymbol{g}_{0}\right)\left(n_{\lambda}\right)^{2} I_{b \lambda}[T(\boldsymbol{x}, t)]$ is intensity of emission from the surface of the opaque layer in semi-transparent, which determine in relation to the intensity $I_{m \lambda}$ and characterize by the unidirectional spectral emissivity $\varepsilon_{\lambda}^{\prime}\left(\boldsymbol{x}, \boldsymbol{g}_{0}\right)$.

Under conditions of thermal equilibrium of surface its absorbing properties also determined by parameter $\varepsilon_{\lambda}^{\prime}\left(\boldsymbol{x}, \boldsymbol{g}_{0}\right)$. Then, the spectral intensity $I_{\lambda}^{a b s}\left(\boldsymbol{x}, t, \boldsymbol{g}_{0}\right)$ absorbed by opaque surface of heat radiation at intensity falling on it $I_{\lambda}^{\text {inc }}\left(\boldsymbol{x}, t, \boldsymbol{g}_{0}\right)$, considering Kirchhoff's law $\left(\varepsilon_{\lambda}^{\prime}\left(\boldsymbol{x}, \boldsymbol{g}_{0}\right)=1-R_{\lambda}^{\prime}\left(\boldsymbol{x}, \boldsymbol{g}_{0}\right)\right.$, represent thus $I_{\lambda}^{a b s}\left(\boldsymbol{x}, t, \boldsymbol{g}_{0}\right)=n_{\lambda}^{2}\left[1-R_{\lambda}^{\prime}\left(\boldsymbol{x}, \boldsymbol{g}_{0}\right)\right] I_{\lambda}^{\text {inc }}\left(\boldsymbol{x}, t, \boldsymbol{g}_{0}\right)$. 
If the temperature $T_{s}$ of the radiation source substantially exceeds the temperature $T$ in the investigated homogeneous semi-transparent body in the literature to describe the propagation of external heat radiation transport equation is used in the approximation of nonradiative material $\left(I_{m \lambda}=0\right)$. The solution of (1) in this case is simplified and has the form $I_{\lambda}\left(\theta_{\lambda}, \boldsymbol{g}_{0}\right)=I_{\lambda}^{\text {ef }}\left(\boldsymbol{x}, \boldsymbol{g}_{0}\right) \exp \left(-\theta_{\lambda}\right)$. Using this approach allows us to separate the problem of determining the radiation field and temperature in a semi-transparent solid. For a semi-transparent layer plate as the "external" is the radiation of the source, if it borders with the environment by exposure to irradiation or radiation from the surface of the contacting opaque layer Such an approach for given restrictions on the temperature was used in the second case, since the maximum energy of the thermal radiation of the opaque layer accounted for the near and far infrared range, where the nature of the absorption is near-surface [4].

Effect of "external" radiation on the semi-transparent layer can be characterized by the temperature factor - volumetric heat generation. In the approximation of the radiating material heat generation in the semi-transparent layer determine the absorbed energy "external" heat radiation, and their expression of the known solutions of systems of Fredholm integral equations of the second kind effective intensity $I_{\lambda}^{e f}$ of radiation at the surface will be [4]

$$
Q=\int_{\lambda=0}^{\infty}\left[a_{\lambda}(\boldsymbol{x}) \int_{\Gamma=4 \pi} I_{\lambda}^{e f}\left(\boldsymbol{x}, \boldsymbol{g}_{0}\right) \exp \left(-\theta_{\lambda}\right) d \Gamma_{\boldsymbol{g}_{0}}\right] d \lambda
$$

In the opaque layer processes of emission and absorption of thermal energy, according to the phenomenological theory consider superficial, and emitted and absorbed energy characterize the corresponding flux $p_{o p}$ and $p_{a b s}$ on surfaces. Their expressions we get integrating the ratio for $I_{\lambda}^{o p}, I_{\lambda}^{a b s}$ over the spectrum and within an angle $\Gamma=2 \pi$

$$
\begin{gathered}
q_{o p}(\boldsymbol{x})=\int_{0}^{\infty}\left\{\int_{\Gamma} \varepsilon_{\lambda}^{\prime}\left(\boldsymbol{x}, \boldsymbol{g}_{0}\right)\left(n_{\lambda}\right)^{2} I_{m \lambda}[T(\boldsymbol{x}, t)] d \Gamma_{\boldsymbol{g}_{0}}\right\} d \lambda, \\
q_{a b s}(\boldsymbol{x})=\int_{0}^{\infty}\left\{\int_{\Gamma}\left[1-R_{\lambda}^{\prime}\left(\boldsymbol{x}, \boldsymbol{g}_{0}\right)\right] I_{\lambda}^{i n c}\left(\boldsymbol{x}, t, \boldsymbol{g}_{0}\right) d \Gamma_{\boldsymbol{g}_{0}}\right\} d \lambda .
\end{gathered}
$$

If the emissivity of the surface considered independent of direction $\boldsymbol{g}_{0}\left(\varepsilon_{\lambda}^{\prime}=\varepsilon_{\lambda}(\boldsymbol{x})\right)$ and wavelength $\lambda$ (diffuse-gray surface), and refractive index - independent of $\lambda$ (in particular, equal to the average interval values in real spectral range $\varepsilon_{\lambda}(\boldsymbol{x})=\varepsilon(\boldsymbol{x}), n_{\lambda}=n=$ const), then from (5) we obtain the Stefan-Boltzmann expression $q_{o p}(\boldsymbol{x})=\varepsilon(\boldsymbol{x})(n)^{2} \sigma T^{4}(\boldsymbol{x}, t)$ ( $\sigma$ is a Stefan-Boltzmann constant) for the flux of thermal energy. Note that for diffuse reflective surfaces (such as transparent or semi-transparent solids) relations $R_{\lambda}^{\prime}\left(\boldsymbol{x}, \boldsymbol{g}_{0}\right)=\pi R_{\lambda}^{\prime \prime}\left(\boldsymbol{x}, \boldsymbol{g}_{0}\right)=R_{\lambda}(\boldsymbol{x})$ are valid, where $R_{\lambda}(\boldsymbol{x})$ is a coefficient of the diffuse reflectance, and for diffuse-gray $R_{\lambda}(\boldsymbol{x})=R(\boldsymbol{x})$. Then the expression (5) is also simplified.

Thermal state of the two-layer plates determined from the system of heat conduction equations that describe heat transfer in layers. At the same time heat generation (3) in a semi-transparent layer, we consider as volumetric heat sources

$$
\kappa T_{, i i}+Q=\rho c_{\varepsilon} \frac{\partial T}{\partial t}
$$

where $\rho, \kappa, c_{\varepsilon}$ are density, thermal conductivity and specific heat of layers. Here and below, the comma preceding indices denotes differentiation in the corresponding coordinates $x_{i}$, and the repeated indexes means summation. For opaque areas in the equations (6) $Q=0$.

The system of equations (6) supplement boundary and contact conditions formulated on the basis of the conditions of continuity of the normal components of the heat flux vectors $\boldsymbol{q}_{(l)}$ on the surfaces of the plate and at the boundary layers (balance conditions), taking on the interface of the assumption of local thermal equilibrium between the layers (the equality of their temperatures). At the same time at the boundary between layers of different transparency or on the surface of the opaque layer, we are 
also considering fluxes $q_{o p}$ and $q_{a b s}$, caused by radiation and absorption heat energy. Form of boundary condition on the radiated surface of the plate depends on the radiative properties of the layer from the side of irradiation. For opaque and semi-transparent layer, such conditions will be respectively [20]

$$
q_{i}^{(T)}=q^{e x t}+q_{o p}-q_{a b s}, \quad q_{i}^{(T)}=q^{e x t} .
$$

Here $q_{i}^{(T)}=-\kappa T, i n_{i}, q^{e x t}$ is the flux caused thermal conductivity and heat transfer with the environment (in particular by convective according to the law $q^{e x t}(\boldsymbol{x}, t)=\alpha_{i}\left[T_{i}(\boldsymbol{x}, t)+T^{e x t}(t)\right]$, where $\alpha_{i}(\boldsymbol{x}, t)$ is the heat transfer coefficients from the surfaces of layers, $T^{e x t}(t)$ is the temperature in the environment). Fluxes of emitted and absorbed energy are determined in accordance with (4), (5) (at $\left.I_{\lambda}^{i n c}\left(\boldsymbol{x}, t, \boldsymbol{g}_{0}\right)=I_{\lambda s}\left(\boldsymbol{x}, t, \boldsymbol{g}_{0}\right)\right)$. Note that on not irradiated surface $q_{a b s}=0$.

The view of the contact conditions depends on the radiative properties of the contacting of the $j$-th and $k$-th layers If the opaque $j$-th and the semi-transparent $k$-th layers are contacted, these contact conditions at the interface will be

$$
\left(\kappa_{(j)} T_{, i}^{(j)}\right) n_{i}+q_{o p}-q_{a b s}=\left(\kappa_{(k)} T_{, i}^{(k)}\right) n_{i}, \quad T^{(j)}=T^{(k)} .
$$

They are the ideal conditions of thermal contact considering the influence of radiation.

Consider a two-layer infinite plate (Fig. 1), formed by layers 1 and 2 (thicknesses $h_{1}$ and $h_{2}$ ). The plate is subjected to thermal radiation intensity $I_{\lambda s}(\nu)$ from the parallel to this layers heated isothermal surface, which temperature $T_{s}$ is considered to be a predetermined. Here $\nu=\cos \xi$, and $\xi$ are acute angles forming the direction of incidence of the rays from the surface of the positive direction of an axis $z$, directed in the direction of external normal to the layer 2. Domaines $z<0$ and $z>h$ (where $\left.h=h_{1}+h_{2}\right)$ of the environment air at a constant temperature $T_{0}$ (equal to the initial) accept transparent, and the surface of the plate $z=0$ and $z=h$ and boundary of the layer separation, $z=h_{1}$ are diffusely reflecting. We consider that heat radiation of the heated isother-

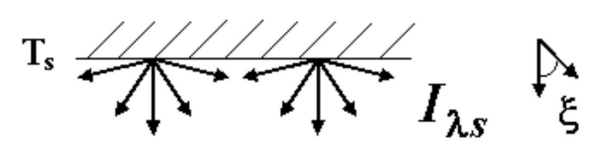

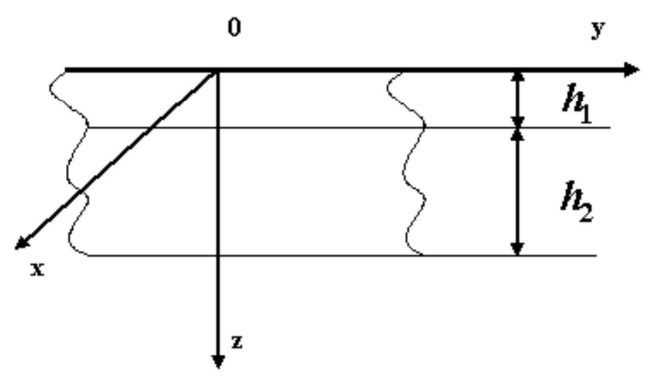

Fig. 1. mal surface is diffuse (intensity independent of the angle $\xi$ ), and it can be described by the relation $I_{\lambda s}=k \frac{2 \pi c_{1}}{\lambda^{5} \exp \left(c_{2} / \lambda T_{s}-1\right)}, k=$ const. The boundary of the contact $z=h_{1}$ is modeled by plane surface with the set on both sides of its radiation characteristics of layer materials.

When describing the propagation of radiation and thermal state in the plate we are using the approach of nonradiating material for semi-transparent layer. Initial relations describing the propagation of radiation and heat transfer in the plate, we will formulate for two variants of the irradiation of the plate.

\section{Irradiation from the side of the opaque layer}

In this case, the system of integral equations (1) formulated relatively effective intensities of radiation $I_{\lambda}^{+(2)}\left(h_{1}, \nu\right), I_{\lambda}^{-(2)}(h, \nu)$ on surfaces of the semi-transparent layer with diffusely reflecting surface has the form

$$
I_{\lambda}^{+(2)}\left(h_{1}, \nu\right)=I_{\lambda}^{(o p)}\left(h_{1}, \nu\right)+I_{\lambda}^{+(r f)}\left(h_{1}, \nu\right), \quad I_{\lambda}^{-(2)}(h, \nu)=I_{\lambda}^{-(r f)}\left(h_{1}, \nu\right), \quad \theta_{\lambda}^{(2)}=a_{\lambda} h,
$$

where

$$
I_{\lambda}^{+(r f)}\left(h_{1}, \nu\right)=2 R_{\lambda}^{+(2)} \int_{0}^{1} I_{\lambda}^{-(2)}\left(h, \nu_{*}\right) \nu_{*} \exp \left[-\theta_{\lambda}^{(2)} / \nu_{*}\right] d \nu_{*}
$$

Mathematical Modeling and Computing, Vol.4, No.1, pp. 21-36 (2017) 


$$
I_{\lambda}^{-(r f)}\left(h_{1}, \nu\right)=2 R_{\lambda}^{-(2)} \int_{0}^{1} I_{\lambda}^{+(2)}\left(h, \nu_{*}\right) \nu_{*} \exp \left[-\theta_{\lambda}^{(2)} / \nu_{*}\right] d \nu_{*}
$$

and the intensity of thermal radiation $I_{\lambda}^{(o p)}\left(h_{1}, \nu\right)$ from the surface of the opaque layer 1 in a semitransparent 2 is given by $I_{\lambda}^{(o p)}\left(h_{1}, \nu\right)=\varepsilon_{\lambda}^{+(1)}\left[n_{\lambda}^{(2)}\right]^{2} I_{b \lambda}\left[T\left(h_{1}, t\right)\right], \varepsilon_{\lambda}^{+(1)}=1-R_{\lambda}^{+(1)}$. Where $R_{\lambda}^{+(2)}, R_{\lambda}^{-(2)}$ are diffuse reflection coefficients at the border of contact and the inner surface of semi-transparent layer; $R_{\lambda}^{+(1)}, \varepsilon_{\lambda}^{+(1)}$ are diffuse reflection coefficients and emissivity of the internal surface of the opaque layer.

The solution of system (9) according the consideration of a single radiation reflection in layer 2 has the form

$$
I_{\lambda}^{+(2)}\left(h_{1}, \nu\right)=A_{1} I_{\lambda}^{(o p)}\left(h_{1}, t\right), \quad I_{\lambda}^{-(2)}(h, \nu)=A_{1} A_{2} I_{\lambda}^{(o p)}\left(h_{1}, t\right) .
$$

Here $A_{1}=1 /\left[1-4 R_{\lambda}^{+(2)} R_{\lambda}^{-(2)} E_{3}^{2}\left(\theta_{\lambda}^{(2)}\right)\right], A_{2}=2 R_{\lambda}^{-(2)} E_{3}^{2}\left(\theta_{\lambda}^{(2)}\right), E_{3}\left(\theta_{\lambda}^{(2)}\right)=\int_{0}^{1} \mu \exp [-x / \mu] d \mu$ is the integroexponential function.

Heat source $Q_{2}$ in layer 2 we determine in accordance (3)

$$
Q(z, t)=2 \pi \int_{0}^{\infty} a_{\lambda}\left\langle\int_{0}^{1}\left\{I_{\lambda}^{+(2)}\left(h_{1}, \nu\right) \exp \left[-a_{\lambda}\left(z-h_{1}\right) / \nu\right]+I_{\lambda}^{2}(h, \nu) \exp \left[-a_{\lambda}(h-z) / \nu\right]\right\} d \nu\right\rangle d \lambda
$$

Heat fluxes $q_{a b s}(0), q_{o p}(0, t)$ on the surface $z=0$ of this layer (which we assume to be diffuse gray), connected with an external source of radiation and absorption of heat from the surface of the radiation given by the expressions (4) and (5).

$$
q_{a b s}(0)=k\left(1-R^{(s)}\right) \sigma T_{s}^{4}, \quad q_{o p}(0, t)=\varepsilon^{(s)} \sigma[T(0, t)]^{4} .
$$

Here $R^{(s)}, \varepsilon^{(s)}$ are the diffuse reflectance and emissivity of this surface. Similar fluxes $q_{o p}\left(h_{1}, t\right), q_{a b s}\left(h_{1}\right)$ on diffuse gray edge contact $z=h_{1}$, will be

$$
\begin{aligned}
q_{o p}\left(h_{1}, t\right) & =\varepsilon^{+(1)}\left(n^{(2)}\right)^{2} \sigma\left[T\left(h_{1}, t\right)\right]^{4}, \\
q_{a b s}\left(h_{1}\right) & =\pi\left(1-R^{+(1)}\right) \int_{\lambda=0}^{\infty}\left\{\int_{0}^{1}\left[I_{\lambda}^{-2}(h, \nu) \exp \left[-\theta_{\lambda}^{2} / \nu\right] \nu d \nu\right]\right\} d \lambda,
\end{aligned}
$$

where the expression for the intensity $I_{\lambda}^{-2}(h, \nu)$ of the effective radiation from the surface $z=h$ of the semi-transparent layer is defined by the formula (9)

Thermal state of the plate (when the density $\rho_{j}$ and thermophysical characteristics of the materials of layers $\kappa_{j}, c_{\varepsilon j}, j=\overline{0,2}$ are the constants), we described by the system of equations (6), which is relatively temperature deviations $\theta_{j}=T_{j}-T_{0}$ in the plate from the initial $T_{0}=$ const has the form

$$
\frac{\partial^{2} \theta_{j}(z, t)}{\partial z^{2}}-\frac{1}{\varpi_{j}} \frac{\partial \theta_{j}(z, t)}{\partial t}=-\frac{Q_{j}(z, t)}{\kappa_{j}}, \quad Q_{1}(z, t)=0, \quad Q_{2}(z, t)=Q(z, t) .
$$

$\left(\varpi_{j}=\kappa_{j} / \rho_{j} c_{\varepsilon j}\right.$ are coefficients of thermal diffusivity of materials of layers. Substituting expressions (12), (13) in (8) we obtain the following contact-boundary conditions for the considered variant of the irradiation (for convective heat transfer)

$$
\begin{aligned}
& \kappa_{1} \frac{\partial \theta_{1}(0, t)}{\partial z}-\alpha_{1} \theta_{1}(0, t)=-k\left(1-R^{(s)}\right) \sigma T_{s}^{4}+\varepsilon^{(s)} \sigma[T(0, t)]^{4} \\
& \kappa_{1} \frac{\partial \theta_{1}\left(h_{1}, t\right)}{\partial z}=\kappa_{2} \frac{\partial \theta_{2}\left(h_{1}, t\right)}{\partial z}+\pi\left(1-R^{+(1)}\right) \int_{\lambda=0}^{\infty}\left\{\int_{0}^{1}\left[I_{\lambda}^{-(2)}(h, \nu) \exp \left[-\theta_{\lambda}^{(2)} / \nu\right] \nu d \nu\right]\right\} d \lambda \\
& -\varepsilon^{+(1)}\left(n^{(2)}\right)^{2} \sigma\left[T\left(h_{1}, t\right)\right]^{4}, \quad \theta_{1}\left(h_{1}, t\right)=\theta_{2}\left(h_{1}, t\right), \quad \kappa_{2} \frac{\partial \theta_{2}(h, t)}{\partial z}+\alpha_{2} \theta_{2}(h, t)=0 .
\end{aligned}
$$




\section{Irradiation from the side of the semi-transparent layer}

In this case, to identify effective intensities $I_{\lambda}^{+(1)}(0, \nu), I_{\lambda}^{-(1)}\left(h_{1}, \nu\right)$ on the surfaces of partially transparent layer 1 we obtain a system of integral equations. The solution of this system according the consideration of a single radiation reflection has the form

$$
I_{\lambda}^{+(1)}(0, v)=B_{1}\left[I_{\lambda}^{(s)}+B_{2} I_{\lambda}^{o p}\left(h_{1}\right)\right], \quad I_{\lambda}^{-(1)}\left(h_{1}, v\right)=B_{1}\left[I_{\lambda}^{o p}\left(h_{1}\right)+B_{2} I_{\lambda}^{(s)}\right]
$$

where $B_{1}=1 /\left[1-4 R_{\lambda}^{+(1)} R_{\lambda}^{-(1)} E_{3}^{2}\left(\theta_{\lambda}^{(1)}\right)\right], B_{2}=2 R_{\lambda}^{-(1)} E_{3}\left(\theta_{\lambda}^{(1)}\right)$, and $I_{\lambda}^{(s)}$ is the intensity of the refracted external radiation. The equations of heat transfer in the plate are heat equations (14) with $Q_{2}=0$,

$$
Q_{1}=2 \pi \int_{0}^{\infty} a_{\lambda}\left\langle\int_{0}^{1}\left\{I_{\lambda}^{+(1)}(0, \nu) \exp \left[-a_{\lambda} z / \nu\right]+I_{\lambda}^{-(1)}\left(h_{1}, \nu\right) \exp \left[-a_{\lambda}\left(h_{1}-z\right) / \nu\right]\right\} d \nu\right\rangle d \lambda .
$$

Having determined the expression of heat fluxes that characterize the radiation from the surface $z=h_{1} ; h$ of the opaque layer 2 in a semi-transparent layer 1 and the environment we obtain such thermal contact and boundary conditions

$$
\begin{aligned}
& \kappa_{1} \frac{\partial \theta_{1}(0, t)}{\partial z}-\alpha_{1} \theta_{1}(0, t)=0 \\
& \kappa_{1} \frac{\partial \theta_{1}\left(h_{1}, t\right)}{\partial z}=\kappa_{2} \frac{\partial \theta_{2}\left(h_{1}, t\right)}{\partial z} \\
& \quad+\pi\left(1-R^{-(2)}\right) \int_{\lambda=0}^{\infty}\left\{\int_{0}^{1}\left[I_{\lambda}^{+(1)}\left(h_{1}, \nu_{*}\right) \exp \left[-\theta_{\lambda}^{(1)} / \nu_{*}\right] \nu_{*} d \nu_{*}\right]\right\} d \lambda-\varepsilon^{-(2)}\left(n^{(1)}\right)^{2} \sigma\left[T\left(h_{1}, t\right)\right]^{4} \\
& \theta_{1}\left(h_{1}, t\right)=\theta_{0}\left(h_{1}, t\right), \quad \kappa_{2} \frac{\partial \theta_{2}(h, t)}{\partial z}+\alpha_{2} \theta_{2}(h, t)+\varepsilon^{(s)} \sigma[T(h, t)]^{4}=0 .
\end{aligned}
$$

$R^{-(1)}, R^{+(1)}, R_{\lambda}^{(s)}$ are the reflection coefficients at the border of contact and internal and external surfaces of semi-transparent layer; $R^{-(2)}, \varepsilon^{-(2)}$ are the reflection coefficient and emissivity of the internal surface of the opaque layer, $\varepsilon^{(s)}$ is the emissivity of the external surface.

Note that if there is an opaque layer in the plate then contact-boundary problem of determining the temperature in it are nonlinear.

\section{Thermostressed state}

In accordance with the distribution of temperature, stress state in two-layer infinite plates is described by relationships temperature problem of elasticity, formulated relatively stress tensor components [3].

$$
\sigma_{x x}^{(j)}=\sigma_{y y}^{(j)}=-\frac{E_{j}}{1-\nu_{j}} \alpha_{t}^{(j)} \theta_{j}+c_{1}^{(j)} z+c_{2}^{(j)}, \quad \sigma_{z z}^{(j)}=0
$$

where $E_{j}$ is Young's modulus, $\nu_{j}$ are Poisson's coefficients, $\alpha_{t}^{(j)}$ are coefficients of linear of temperature expansion of materials layers. For example, when the plate is rigidly clamped at the edges.

$$
\begin{aligned}
c_{1}^{(j)} & =0, \quad c_{2}^{(1)}=\frac{S}{h_{1}+h_{2} / K_{12}}, \quad c_{2}^{(2)}=c_{2}^{(1)} / K_{12}, \\
K_{12} & =\frac{E_{1}}{\left(1-\nu_{1}\right)} \frac{\left(1-\nu_{2}\right)}{E_{2}}, \quad S=\frac{E_{1}}{1-\nu_{1}} \int_{0}^{h_{1}} \alpha_{t}^{(1)} \theta_{1} d z+\frac{E_{2}}{1-\nu_{2}} \int_{h_{1}}^{h} \alpha_{t}^{(2)} \theta_{2} d z .
\end{aligned}
$$

If it is rigidly fixed $-c_{1}^{(j)}, c_{2}^{(j)}=0$. 


\section{Numerical study of heat and stress state}

\section{Irradiation from the side of the opaque layer}

Using the method of the type of Green's functions [12,36-38], solution of the formulated nonlinear contact-boundary problem is reduced to solving an equivalent system of nonlinear integral time Volterra equations. This transformation is carried out using Green's functions $K_{j}\left(z, z^{\prime}, t-t_{0}\right)$, which for the considered heat equations are as follows

$$
K_{j}\left(z, z^{\prime}, t-t_{0}\right)=\frac{\sqrt{\kappa_{j}}}{\sqrt{\pi\left(t-t_{0}\right)}} \exp \left\{-\frac{\left(z-z^{\prime}\right)^{2}}{4 \kappa_{j}\left(t-t_{0}\right)}\right\} .
$$

Then, taking into account the boundary and contact conditions, a system of non-linear integral equations for determining the temperature in the plate was obtained:

$$
\begin{aligned}
\theta_{1}(z, t)= & \theta_{*}(z, t)+\frac{1}{\kappa_{1}} \int_{0}^{t}\left\langle K_{1}\left(0, z, t-t_{0}\right)\left\{\sigma \varepsilon\left[\theta_{1}\left(0, t_{0}\right)+T_{0}\right]^{4}+\alpha_{1}, \theta_{1}\left(0, t_{0}\right)\right\}\right. \\
& \left.+K_{1}\left(h_{1}, z, t-t_{0}\right)\left\{\sigma \varepsilon\left[\theta_{1}\left(h_{1}, t_{0}\right)+T_{0}\right]^{4}+\kappa_{2} \frac{\partial \theta_{2}\left(h_{1}, t_{0}\right)}{\partial z}-\pi \int_{0}^{\infty} I_{\lambda}^{(0) a b s} d \lambda\right\}\right\rangle d t_{0}, \\
\theta_{2}(z, t)=- & \int_{0}^{t}\left[K_{2}\left(h_{1}, z, t-t_{0}\right) \frac{\partial \theta_{2}\left(h_{1}, t_{0}\right)}{\partial z}+K_{2}\left(h, z, t-t_{0}\right) \alpha_{2} \theta_{2}\left(h, t_{0}\right)\right] d t_{0}-\Phi\left[z, t, \theta_{1}\left(h_{1}, t\right)\right] .
\end{aligned}
$$

Here

$$
\begin{aligned}
\theta_{*}(z, t)= & \frac{1}{\kappa_{1}} \int_{0}^{t} K_{1}\left(0, z, t-t_{0},\right) k \sigma \varepsilon T_{s}^{4} d t_{0}, \\
\Phi\left(z, t, \theta_{1}\left(h_{1}, t\right)\right)= & \frac{1}{4 \pi \kappa_{2}} \int_{0}^{t} \int_{h_{1}}^{h} K_{2}\left(z, z^{\prime}, t-t_{0}\right) Q\left(z^{\prime}, t_{0}\right) d z^{\prime} d t_{0} \\
& -\frac{\pi}{\kappa_{1}} \int_{0}^{t} K_{1}\left(h_{1}, z, t-t_{0}\right)\left[\int_{0}^{\infty} I_{\lambda}^{(0) a b s} d \lambda\right] d t_{0} .
\end{aligned}
$$

Determination of temperature in the plate from the system of equations (22), (23) include the determination of the temperature at the base plate and layer interface. Substituting values $z=0 ; h_{1}$ in equation (22) and $z=h_{1}, h$ in equation (23), and excluding the value $\partial\left[\theta_{2}\left(h_{1}, t_{0}\right)\right] / \partial z$ we obtain a system of three nonlinear integral equations of Volterra type in time for the quantities $\theta_{1}(0, t), \theta_{1}\left(h_{1}, t\right)$, $\theta_{2}(h, t)$ :

$$
\begin{aligned}
\theta_{1}(0, t)= & \theta^{(1)}(0, t)+\int_{0}^{t}\left\{\frac{1}{\kappa_{1}} C\left(\theta_{1}(0, t)\right)\left[K_{1}\left(0,0, t-t_{0}\right)-\frac{\kappa_{2} K_{1}^{2}\left(0,0, t-t_{0}\right)}{\left(\kappa_{1}+\kappa_{2}\right) K_{1}\left(h_{1}, h_{1}, t-t_{0}\right)}\right]\right. \\
& \left.+\frac{1}{\left(\kappa_{1}+\kappa_{2}\right)}\left[K_{1}\left(h_{1}, 0, t-t_{0}\right) D\left(\theta_{1}\left(h_{1}, t_{0}\right)\right)-\frac{\kappa_{1} K_{2}\left(h_{1}, h, t-t_{0}\right)}{K_{1}\left(h_{1}, h_{1}, t-t_{0}\right)} E\left(\theta_{2}\left(h, t_{0}\right)\right)\right]\right\} d t_{0}, \\
\theta_{1}\left(h_{1}, t\right)= & \theta^{(2)}\left(h_{1}, t\right)+\frac{1}{\left(\kappa_{1}+\kappa_{2}\right)} \int_{0}^{t}\left[C\left(\theta_{1}\left(0, t_{0}\right)\right) K_{1}\left(0, h_{1}, t-t_{0}\right)\right. \\
& \left.+D\left(\theta_{1}\left(h_{1}, t_{0}\right)\right) K_{1}\left(h_{1}, h_{1}, t-t_{0}\right)-\kappa_{2} K_{2}\left(h_{1}, h_{2}, t-t_{0}\right) E\left(\theta_{2}\left(h, t_{0}\right)\right)\right] d t_{0}, \\
\theta_{2}(h, t)= & \theta^{(3)}(h, t)-\frac{1}{\kappa_{1}+\kappa_{2}} \int_{0}^{t}\left[\frac{K_{1}\left(h_{1}, 0, t-t_{0}\right) K_{2}\left(h_{1}, h, t-t_{0}\right)}{K_{1}\left(h_{1}, h_{1}, t-t_{0}\right)} C\left(\theta_{1}\left(h_{1}, t_{0}\right)\right)\right. \\
& \left.+K_{1}\left(h_{1}, h, t-t_{0}\right) D\left(\theta_{1}\left(h_{1}, t_{0}\right)\right)-\left(\kappa_{1}+\kappa_{2}\right) K_{2}\left(h, h, t-t_{0}\right) E\left(\theta_{2}\left(h, t_{0}\right)\right)\right] d t_{0},
\end{aligned}
$$


where

$$
\begin{aligned}
& \theta^{(1)}(0, t)=\theta_{*}(0, t)+\frac{\kappa_{2}}{\kappa_{1}+\kappa_{2}} \int_{0}^{t} \frac{K_{1}\left(0, h_{1}, t-t_{0}\right)}{K_{1}\left(h_{1}, h_{1}, t-t_{0}\right)}\left[\Phi\left(h_{1}, t, \theta_{1}\left(h_{1}, t\right)\right)-k \sigma \varepsilon T_{s}^{4} K_{1}\left(0, h_{1}, t-t_{0}\right)\right] d t_{0}, \\
& \theta^{(2)}\left(h_{1}, t\right)=\Phi\left(h, t, \theta_{1}\left(h_{1}, t\right)\right)-\frac{\kappa_{2}}{\kappa_{1}+\kappa_{2}} \int_{0}^{t}\left[\Phi\left(h_{1}, t, \theta_{1}\left(h_{1}, t\right)\right)-\frac{k \sigma \varepsilon T_{s}^{4}}{\kappa_{1}} K_{1}\left(0, h_{1}, t-t_{0}\right)\right] d t_{0}, \\
& \theta^{(3)}(h, t)=\Phi\left(h, t, \theta_{1}\left(h_{1}, t\right)\right)-\frac{\kappa_{1}}{\kappa_{1}+\kappa_{2}} \int_{0}^{t} \frac{K_{2}\left(h_{1}, h, t-t_{0}\right)}{K_{1}\left(h_{1}, h_{1}, t-t_{0}\right)}\left[\Phi\left(h_{1}, t, \theta_{1}\left(h_{1}, t\right)\right)-\right. \\
& \left.-\frac{k \sigma \varepsilon T_{s}^{4}}{\kappa_{1}} K_{1}\left(0, h_{1}, t-t_{0}\right)\right] d t_{0}, \\
& C\left(\theta_{1}\left(0, t_{0}\right)\right)=\sigma \varepsilon\left[\theta_{1}\left(0, t_{0}\right)+T_{0}\right]^{4}+\alpha_{1} \theta_{1}\left(0, t_{0}\right), \\
& D\left(\theta_{1}\left(h_{1}, t_{0}\right)\right)=\sigma \varepsilon n^{2}\left[\theta_{1}\left(h_{1}, t_{0}\right)+T_{0}\right]^{4}, \quad E\left(\theta_{2}\left(h, t_{0}\right)\right)=\alpha_{2} \theta_{2}\left(h, t_{0}\right) .
\end{aligned}
$$

The system of equations (25) was solved by the method of successive approximations, whose convergence for a obtained non-linear system of Volterra integral equations was proved in the paper [38]. To do this, we write the system (25) in vector form

$$
\boldsymbol{\theta}(t)=\boldsymbol{\theta}^{(0)}+\int_{0}^{t} \boldsymbol{F}\left[t, t_{0}, \boldsymbol{\theta}\left(t_{0}\right)\right] d t_{0}
$$

where $\boldsymbol{\theta}^{(0)}=\left\{\theta^{(1)}(0, t), \theta^{(2)}\left(h_{1}, t\right), \theta^{(3)}(h, t)\right\}$, and components of the vector $\boldsymbol{F}$ are, respectively, the integrand in the first, second and third equations of system (25). Then the sequence of Picard, which determines the solution of the system is described as follows

$$
\boldsymbol{\theta}_{(0)}(t)=\boldsymbol{\theta}^{(0)}, \quad \boldsymbol{\theta}_{(n)}=\boldsymbol{\theta}_{(0)}+\int_{0}^{t} \boldsymbol{F}\left[t, t_{0}, \boldsymbol{\theta}_{(n-1)}\left(t_{0}\right)\right] d t_{0}, \quad n=1,2, \ldots
$$

When the solution of the system (25) is found, then the solution of the initial nonlinear contactboundary problem is defined by quadrature from (22), (23).

Numerical studies is conducted for plate consisting of a opaque layer of stainless steel H18N9TL and semi-transparent layer of glass S95-3, the absorption coefficient which is still approximated by piecewise constant function $[5,21]$.

Characteristics of glass S95-3 and the stainless steel H18N9TL [39-41] are the following:

$$
\begin{aligned}
\text { H18N9TL: } \varepsilon & =0.2 ; \\
\kappa & =16.7 \mathrm{~W} /(\mathrm{K} \cdot \mathrm{m}), \quad \varpi=4.22 \cdot 10^{-6} \mathrm{~m}^{2} / \mathrm{s}, \quad \alpha=50 \mathrm{~W} /\left(\mathrm{m}^{2} \cdot \mathrm{K}\right) ; \\
E & =198 \mathrm{GPa}, \quad \nu=0.28, \quad \alpha_{t}=0.17 \cdot 10^{-4} \mathrm{~K}^{-1} . \\
\text { S95-3: } R & =0.02, \quad \lambda_{n}=273 \mu m, \quad a_{1}=150 \mathrm{~m}^{-1}, \quad a_{1}=900 \mathrm{~m}^{-1}, \\
\kappa & =1.6 \mathrm{~W} /(\mathrm{K} \cdot \mathrm{m}), \quad \varpi=8 \cdot 10^{-7} \mathrm{~m}^{2} / \mathrm{s}, \\
\alpha & =26 \mathrm{~W} /\left(\mathrm{m}^{2} \cdot \mathrm{K}\right), \quad E=65.4 \mathrm{GPa}, \quad \nu=0.215 .
\end{aligned}
$$

The plate is heated by radiation with the intensity $I=\int_{0}^{\infty} I_{\lambda s} d \lambda=1.5 \cdot 10^{5} \mathrm{~W} / \mathrm{m}^{2} \cdot s r$, which corresponds, in particular, the temperature of the radiating surface $T_{s}=1960 \mathrm{~K}$ with a coefficient of proportionality $k=1$. Heating time is determined by the condition that the temperature on the surface of contact is not exceeded 720 (temperature transformation of the glass).

For the plate with the thicknesses of layers $h_{1}=h_{2}=0.01 \mathrm{~m}$ Fig. 2 shows the temperature change on the surface of the plate $z=0 \mathrm{~m}$ (curves 1 ), $z=0.02 \mathrm{~m}$ (curves 3) and contact surface $z=0.01 \mathrm{~m}$ (curves 2) by time. The dashed curves correspond to calculations without taking into account the radiation opaque layer of thermal energy. It is evident that the effect of heat radiation of the opaque 
layer on the calculated plate temperature is observed at the temperatures higher $530 \mathrm{~K}$. It is more significant on the surface $z=0$ and decreases in depth of the plate.

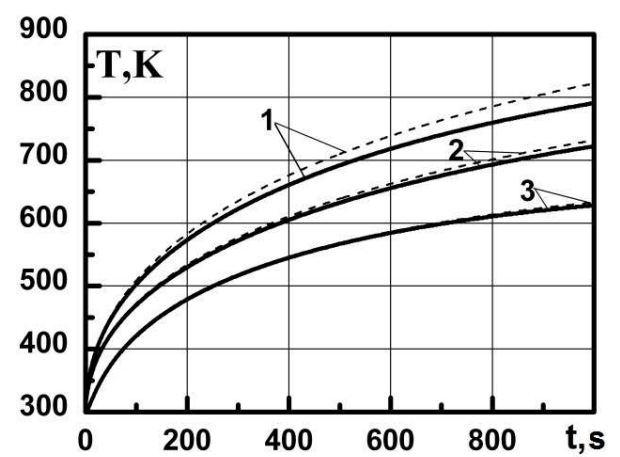

Fig. 2.

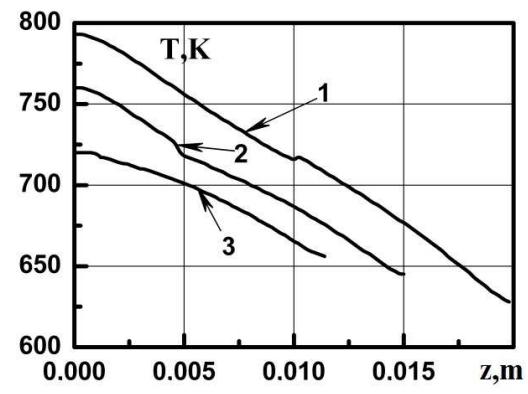

$a$

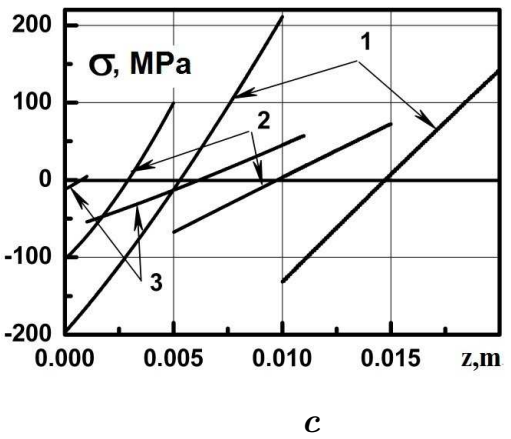

Fig. $3 a$ presents the temperature distribution in thickness of the plate at a fixed thickness of the glass layer $h_{2}=0.01 \mathrm{~m}$ and variable of metal layer (curve $1-h_{1}=$ $0.01 \mathrm{~m}$; curve $2-h_{1}=0.005 \mathrm{~m}$; curve $\left.3-h_{1}=0.001 \mathrm{~m}\right)$. The time of heating, in which the maximum temperature in the glass layer does not exceed the glass transformation temperature respectively are $t=1000,820$ and $690 \mathrm{~s}$. The distribution of temperatures for the fixed-length of the metal layer $h_{1}=0.01 \mathrm{~m}$ and variable of glass layer (curve 1 $-h_{2}=0.005 \mathrm{~m}$; curve $2-h_{2}=0.007 \mathrm{~m}$; curve $3-$ $h_{2}=0.01 \mathrm{~m}$ ) illustrated in Fig. $3 b$. The times of heating were 827,846 and $827 \mathrm{~s}$.
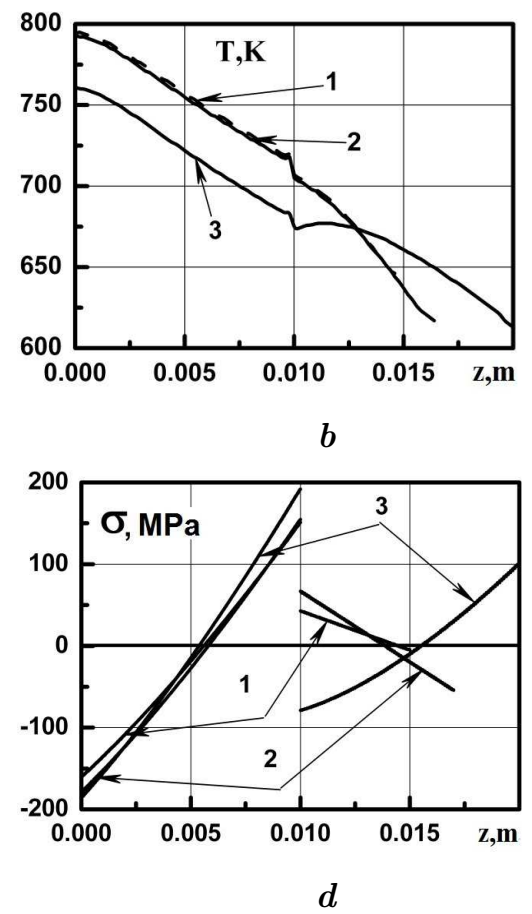

Fig. 3.

During heating this plate, the temperature decreases in depth (Fig. 2, 3), its change in thickness depends on the heating time (Fig. 2) and the relationships between the thicknesses of the layers (Fig. 3). By reducing the thickness of the semi-transparent layer and leaving a constant thickness of the opaque layer, we observe the growth in the temperature difference of semi-transparent layer (curves 1, 2 Fig. $3 b$ ), which is explained by way of the heating the plate with consideration of heat exchange with the environment conditions. In the neighborhood of the contact surface there is a fracture curves describing the temperature of the plate (Fig. 3).

Impact of the thermal radiation of the opaque layer on the calculated temperature of the plate is observed at temperatures 530. It is most significant at the surface $z=0$ and decreases in depth of the plate (dashed curves in Fig. 2).

Valid values for the tensile stresses of the materials constituting the parts of the plate (which is a typical opaque and semi-transparent materials) are $400 \ldots 500$ and $60 \ldots 100 \mathrm{MPa}$ respectively for steel H18N9TL and for glass S95-3. Therefore, the state of stress in the plate can be assessed by the level of 
the tensile stresses in the partially semi-transparent layer. When the fixed thickness of the glass layer is $h_{2}=0.01 \mathrm{~m}$, a maximum tensile stresses reach $\left(\right.$ at $h_{1} \leqslant h_{2}$ ) in the metallic (curve $1 \mathrm{Fig}$. $3 \mathrm{c}$ ). Their level decreases with decreasing length of the metal layer (curves 2, $3 \mathrm{Fig} .3 \mathrm{c}$ ). In this case the tensile stress in the glass is insignificant $(20 \ldots 25 \mathrm{MPa})$. For a fixed length $h_{1}=0.01 \mathrm{~m}$ metal layer considering changing the thickness of glass (at $h_{2} \leqslant h_{1}$ ) stress distribution is qualitatively different character stretching tension localized in glass (curves 1, 2 Fig. $3 d$ ). For a certain thickness $h_{2}=0.007 \mathrm{~m}$ of the glass layer and the heating time $t=827 \mathrm{~s}$ level of tensile stresses reaches the allowable values (curve 2 Fig. $3 d$ ). On the surface of the contact of the layers the stresses change abruptly. A size of a jump increases with increasing thickness of the plate.

\section{Irradiation from the side of the semi-transparent layer}

In this case, the thermal state of the plate will be described by the equations (14) $(j=1,2)$ with $Q_{2}=0$ and $Q_{1}$ is described by formula (17). The contact-boundary conditions is written in the assumption of the diffuse-gray surfaces

$$
\begin{aligned}
& \kappa_{1} \frac{\partial \theta_{1}(0, t)}{\partial z}-\alpha_{1}\left[\theta_{1}(0, t)\right]=0 \\
& \kappa_{1} \frac{\partial \theta_{1}\left(h_{1}, t\right)}{\partial z}=\kappa_{2} \frac{\partial \theta_{2}\left(h_{1}, t\right)}{\partial z}+q_{a b s}\left[h_{1}, \theta_{2}\left(h_{1}, t\right), T_{s}\right]-\varepsilon^{-(2)}\left[n^{(1)}\right]^{2} \sigma\left[\theta_{2}\left(h_{1}, t\right)+T_{0}\right]^{4}, \\
& \theta_{1}\left(h_{1}, t\right)=\theta_{2}\left(h_{1}, t\right) \\
& \frac{\partial \theta_{2}(h, t)}{\partial z}+\alpha_{2}\left[\theta_{2}(h, t)\right]+\varepsilon^{(s)} \sigma\left[\theta_{2}(h, t)+T_{0}\right]^{4}=0
\end{aligned}
$$

were

$$
q_{a b s}\left[h_{1}, \theta\left(h_{1}, t\right), T_{s}\right]=\pi\left(1-R^{-(1)}\right) \int_{\lambda=0}^{\infty}\left\{\int_{0}^{1}\left[I_{\lambda}^{+(1)}\left(h_{1}, \nu\right) \exp \left(-a_{\lambda}^{(1)} h_{1} / \nu\right) \nu d \nu\right]\right\} d \lambda .
$$

As before $h=h_{1}+h_{2}$. The contact condition (28) contains (as a boundary condition (30)), non-linearity associated with the fourth degree of the temperature.

To solve the nonlinear contact-boundary problem of the transient heat conduction (27)-(30) by finite difference method $[42,43]$ linearize the nonlinear contact (28) and boundary (30) conditions with the temperature of the fourth degree of, using the procedure quasilinearization [44].

Numerical studies were conducted for a plate consisting of a semi-transparent layer of glass BS-37A and an opaque layer of stainless steel H18N9TL.

We have considered the temperature $T_{s}$ of the radiating surface $1000 \mathrm{~K}$ or $3000 \mathrm{~K}$. The integral flux $I=\int_{0}^{\infty} I_{\lambda s} d \lambda$ from it in the direction of the plate were selected (changing the coefficient $k$, so that the temperature in the glass layer of thickness $h_{1} \leqslant 0.01 \mathrm{~m}$ when the thickness of the metal $h_{2}=0.01 \mathrm{~m}$, for the considered intensity radiations for 4 hours did not exceed the temperature of the glass transformation $-720 \mathrm{~K}$.

Characteristics of glass BS-37A are the following:

$$
\begin{gathered}
R=0.02, \quad n=1.66, \quad \lambda_{n}=4.8 \mu \mathrm{m}, \quad a_{1}=70 \mathrm{~m}^{-1}, \quad a_{2}=900 \mathrm{~m}^{-1}, \\
\kappa=1.38 \mathrm{~W} /(\mathrm{K} \cdot \mathrm{m}), \quad \varpi=5.7 \cdot 10^{-7} \mathrm{~m}^{2} / \mathrm{s}, \quad \alpha_{t}=9.3 \cdot 10^{-6} \mathrm{~K}^{-1}, \\
\alpha=22.4 \mathrm{~W} /\left(\mathrm{m}^{2} \cdot \mathrm{K}\right), \quad E=103 \mathrm{GPa}, \quad \nu=0.277 .
\end{gathered}
$$

Distribution of the heat source, $Q_{*}(z)=Q_{1}(z) / Q_{1}(0)$ (in steady mode temperature) in thickness of the semi-transparent layer when the thicknesses of the component parts $h_{1}=0.001 \mathrm{~m}, h_{2}=0.01 \mathrm{~m}$ shown in Fig. 4a. Curves 1-3 correspond to the values of the reflection coefficient $R^{-(1)}$ at the interface between the glass-steel $0.5 ; 0.65 ; 0.8$ (the solid curves for $T_{s}=1000 \mathrm{~K}$, and the dashed - for $T_{s}=$ 
$3000 \mathrm{~K})$. Note that this value may depend on the surface roughness of opaque material, method of connection components plate and so on. The value of 0.8 is typical for polished steel H18N9TL. We see that the level of heat source in the neighborhood of contact surface increases with increasing the reflection coefficient. Hence, character of the distribution of the heat release is determined not only by the absorption properties of the glass material layer and by the temperature of the radiation source, but also by the properties of the contact surface. Distribution of $Q_{*}$ at $h_{1}=0.01 \mathrm{~m}, h_{2}=0.01 \mathrm{~m}$ and $R^{-(1)}=0.8$ and $T_{s}=1000,3000 \mathrm{~K}$ shown in Fig. $4 b$ by curves 1,2 respectively. Dashed lines were obtained in the case of ignoring heat energy radiation by opaque element at the contact surface.
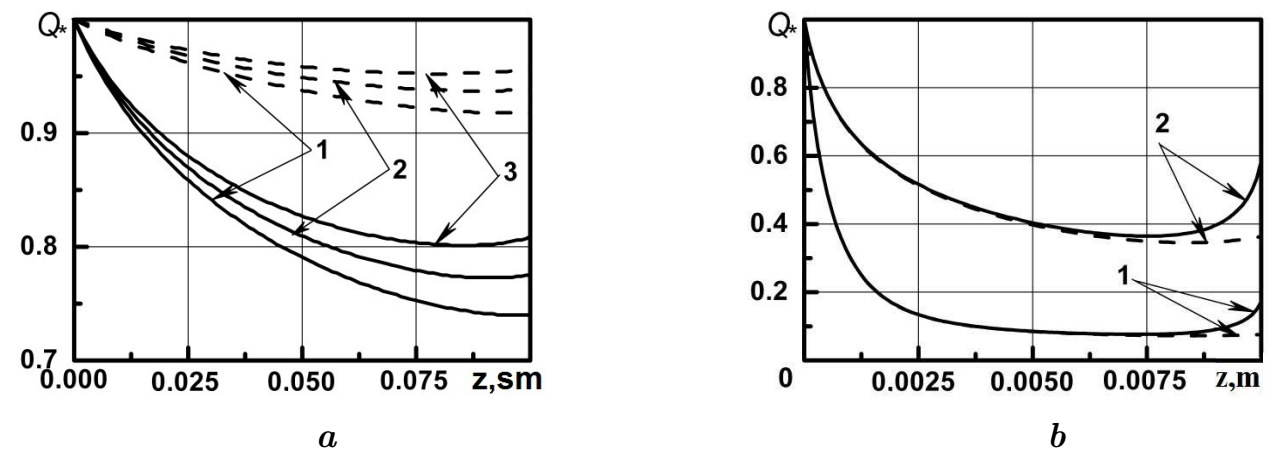

Fig. 4.

As we see, ignoring radiation in thermal contact conditions significantly alters the distribution heat source in the neighborhood of the contact, in particular, leads to an underestimation of their.

From the analysis of graphs in Fig. $4 a, 4 b$ follows that the unevenness of the heat releases in the glass layer increases with increasing its thickness and with decreasing temperature sources.

On Fig. $5 a, 5 b$ submitted distribution of temperature and stresses by solid and by dashed lines $\sigma=\sigma_{x x}=\sigma_{y y}$ (at steady state) in thickness plates by heating source with temperature $1000 \mathrm{~K}$ and $3000 \mathrm{~K}$ at $R^{-(1)}=0.8$. The bases of the plates are free from efforts and moments. The coefficient $k$ for those temperatures was chosen equal 0.028 and 0.00035 . Curves $1-3$ correspond to different thicknesses of glass when the thicknesse of the steel layer $h_{2}=0.01 \mathrm{~m}$ is fixed, namely $h_{1}=0.003 \mathrm{~m}$ $0.005 \mathrm{~m}, 0.007 \mathrm{~m}$.

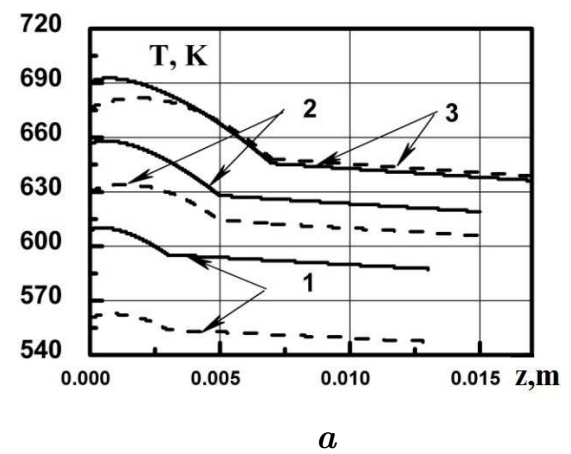

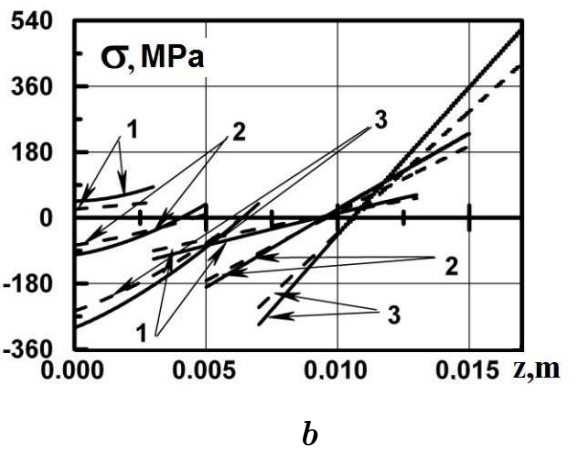

Fig. 5.

We see that the gradient of heating of the plate increases with decreasing temperature of the source from $3000 \mathrm{~K}$ up to $1000 \mathrm{~K}$, and at a fixed temperature - with the increasing glass thickness. Should be noted that the calculated curves of temperature distribution in the plate and known experiment of its values on the surface, we can estimate the radiation characteristics on the border between the layers.

In consideration of thicknesses and source temperatures in both layers there are the zones of tensile and compressive stresses. The maximum of the tensile stresses levels are achieved according to the 
thickness of the glass layer at the contact surface therein or on the surface of the metal, and compressing - on the surfaces of contact to the metal layer or on the surface of the glass. On the surface of contact there is the jump of stresses. The value of the jump increases with increasing thickness of the glass layer.

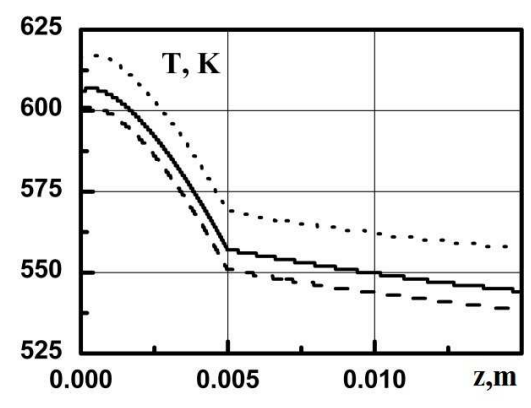

$\boldsymbol{a}$

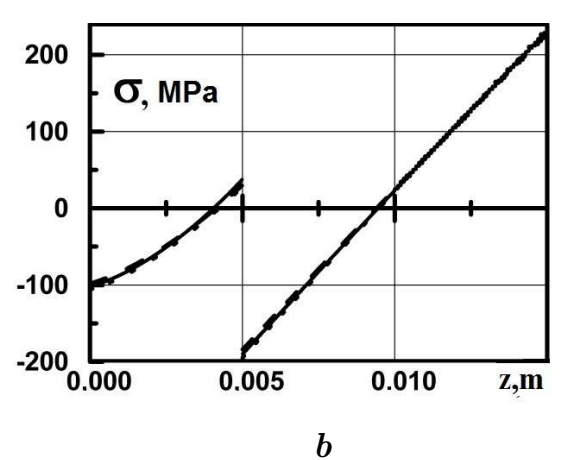

$b$

Fig. 6.

In Fig. 6 depicted distributions of temperature and stresses in the plate $\left(h_{1}=0.005 \mathrm{~m}, h_{2}=0.01 \mathrm{~m}\right)$ for $R^{-(1)}=0.8$ obtained on the basis formulated nonlinear contact-boundary problem (solid lines), nonlinear neglecting of the radiation from the surface of contact (dashed lines) and the linear when the heat radiation of the opaque part discarded (dot-dash line). The dashed and dash-dotted curves point to the fact that neglecting the effects of thermal radiation in the formulation of contact problems for layered irradiated elements (which contain opaque components) influences the calculated values of the temperature and stresses.

\section{Conclusions}

1. Initial relations are obtained for describing the propagation of radiation and heat transfer in irradiated two-layer plates with components of different transparency under the assumption of an ideal contact between the constituent layers at which the contact boundary is simulated by a plane surface with the radiation characteristics of the layer material specified on both sides of it and the thermal contact conditions are ideal.

2. Methods for solving new nonlinear contact-boundary problems of thermoelasticity that arise in describing heat transfer processes in two-layer irradiated plates and investigating their thermomechanical behavior are proposed. In determining the thermal state, they are based on methods: reduction of one-dimensional spatial coordinates of contact-boundary heat conduction problems to the solution of an equivalent nonlinear system of integral time equations of Volterra type using of functions of the Green's functions; quasi-linearization of nonlinear boundary and contact conditions; successive approximations and finite differences using the implicit difference scheme and the sweep method for solving systems of linear algebraic equations In this case, the characteristics of the thermally stressed state in the layers are determined by an analytical-numerical method (using numerical integration) on the basis of analytical expressions obtained from the solution of the temperature contact problem of the theory of elasticity.

3. Based on the analysis of the solutions found, a number of new regularities in temperature distributions and stress tensor components in irradiated layered plates, depending on the fixing conditions, the radiation properties of the constituents.

[1] Hachkevych O. R., Terlets'kyi R. F., Kournyts'kyi T. L. Mechanothermodiffusion in semi-transparent solids. Lviv, SPOLOM, (2007), (in Ukrainian). 
[2] Adrianov V. N. Fundamentals of Radiation and Complex Heat Transfer. Moscow, Energija, 464 p. (1972), (in Russian).

[3] Grigorjev B. A. Pulse heating radiations. Moscow, Nauka, Vol.1, 320 p. (1974), (in Russian).

[4] Rubtsov N. A. Radiation heat transfer in continuous media. Novosibirsk, Nauka, 277 p. (1984), (in Russian).

[5] Siegel R, Howell J. Thermal radiation heat transfer. Moscow, Mir, 935 p. (1975), (in Russian).

[6] Anderson E. E., Viskanta R. Effective Thermal Conductivity for Heat Transfer Through Semitransparent Solids. J. Am. Ceram. Soc. 56, n.10, 541-546 (1973).

[7] Hachkevych O. R., Terlets'kyi R. F. Models of thermomechanics of magnetized and polarized electrically conductive deformable solids. Phys.-Chem. Mechanics of Materials. 40, n.3, 19-37. (2004), (in Ukrainian).

[8] Hachkevych O. R., Musij R. S., Melnik N. B. Thermomechanical behavior of electrically conductive hollow cylinder with pulsed electromagnetic action. Math. Methods and Phys.-Mech. Fields. 44, n.1, 146-154 (2001), (in Ukrainian).

[9] Postol'nyk Y. S., Ogurtsov A. P. Applied Nonlinear thermomechanics. Kyiv. 280 p. (2000), (in Ukrainian).

[10] Ho C.-H., Özişik M. N. Combined conduction and radiation in a two-layer planar medium with flux boundary condition. Num. Heat Transfer. 11, n.3, 321-340 (1987).

[11] Ho C.-H., Özişik M. N. Simultaneous conduction and radiation in a two-layer planar medium. J. Thermophys. Heat Transfer. 1, n.2, 154-161 (1987).

[12] Siegel R. Two flux Green's function analysis for transient spectral radiation in a composite. J. Thermophys. Heat Transfer. 10, n.4, 681-688 (1996).

[13] Tan H.-P., Wang P.-Y., Xia X.-L. Transient coupled radiation and conduction in an absorbing and scattering composite layer. J. Thermophys. Heat Transfer. 14, n.1, 77-87 (2000).

[14] Timoshenko V.P., Trener M. G. A method for evaluting heat transfer in multilayer semi-transparent materials. Heat Transfer-Soviet Research. 18, 321-340 (1986).

[15] Tsai C.-F., Nixon G. Transient temperature distribution of a multilayer composite wall with effects of internal thermal radiation and conduction. Num. Heat Transfer. 10, n.1, 95-101 (1986).

[16] Wang P.-Y., Cheng H.-E., Tan H.-P. Transient thermal analysis of semitransparent composite layer with an opaque boundary. Int. J. Heat Mass Transfer. 45, n.2, 425-440 (2002).

[17] Popovych V.S. Models and methods of calculation thermostressed state of thermo sensitive structural elements under complex conditions of heat transfer: Dis... Doctor. Sc. Science. Luts'k, 312 p. (2005), (in Ukrainian).

[18] Popovych V.S. Construction of the solutions of the problems of thermoelasticity thermosensitive solids under the conditions of convective-radiant heat exchange. Reports of National Academy of Sciences of Ukraine. 11, 69-73 (1997), (in Ukrainian).

[19] Popovych V.S., Harmatij H. Y., Vovk O. M. Thermoelastic state of a thermosensitive hollow sphere under the conditions of convective-radiant heat exchange with the environment. Phys.-Chem. Mechanics of Materials. 42, n.6, 39-48 (2006), (in Ukrainian). [Popovych V. S., Harmatij H. Y., Vovk O. M. Thermoelastic state of a thermosensitive hollow sphere under the conditions of convective-radiant heat exchange with the environment. Materials Science. 42, n.6, 756-770 (2006)].

[20] Bruchal M. B., Terlets'kyi R. F., Turii O. P. Thermomechanics problems for irradiated solids. Theoretical and Applied Mechanics. 4, n.50, 30-37 (2012), (in Russian).

[21] Terlets'kyi R.F., Turii O.P. Modeling and investigation of heat transfer in plates with thin coatings with regard for the influence of radiation. J. of Mathematical Sciences. 192, n.6, 703-722 (2013).

[22] Turii O.P. Nonlinear contact boundary problem of thermomechanics for the irradiated two-layer plate connected by an intermediate layer. Physico-Mathematical Modelling And Informational Technologies. 9, 118-132 (2009), (in Ukrainian).

[23] Kushnir R. M., Popovych V. S., Vovk O. M. The thermoelastic state of a thermosensitive sphere and space with spherical cavity subject to complex heat exchange. J. Eng. Math. 61, n.2, 357-369 (2008).

[24] Popovych V.S., Vovk O. M. The method of solving convective-radiant heat exchange between the cylindrical and N-corner prismatic shells. Math. Methods and Phys.-Mech. Fields. 47, n.1, 158-168 (2004), (in Ukrainian). 
[25] Hachkevych O. R., Bojchuk V. Y. Thermal stress of a long cylinder when heated by thermal radiation. Applied Mechanics. 23, n.4, 16-23 (1987), (in Russian).

[26] Hachkevych O. R., Bojchuk V.Y. Thermomechanical behavior of nonmetallic electrically conductive bodies under high-temperature treatment. Math. Methods and Phys.-Mech. Fields. 39, n.1, 74-79 (1996), (in Russian).

[27] Koljano Y. M., Kulyk A. N. Temperature stresses from volumetric sources. Kyiv, Naukova Dumka, 288 p. (1983), (in Russian).

[28] Pljacko G. V., Podstryhach Ya. S. On the state of stress caused by a laser beam in the process of destruction of transparent polymers. Phys.-Chem. Mechanics of Materials. 6, n.3, 93-97 (1970), (in Russian).

[29] Hetnarski R. B., DeBoltF. C. Thermal stresses due to laser radiation. Part 1: Heat conduction. J. Thermal Stresses. 15, n.2, 331 (1992).

[30] Hetnarski R. B., Hector L. G., Hosseini Tehrani P., Eslami M. R. Thermal stresses due to a laser pulse train: Coupled solution. Proc. 3rd Int. Congress on Thermal Stresses. Cracow (Poland), 61-64 (1999).

[31] Uglov A. A., Koljano Y. M., Kulyk A. N., Stookuj F. I. Stresses in planar solids with absorption under the action of a local heat source. Physics And Chemistry Of Material Processing. 6, 117-120 (1976), (in Russian).

[32] Koljano Y. M., Bernar I. I. Temperature stresses in the plate with two-sided laser treatment. Strength Problems. 5, 36-48 (1983), (in Russian).

[33] Muresan Cr., Vaillon R., Menezo C., Morlot R. Discrete ordinates solution of coupled conductive radiative heat transfer in a two-layer slab with Fresnel interfaces subject to diffuse and obliquely collimated irradiation. Journal of Quantitative Spectroscopy and Radiative Transfer. 84, n.4, 551-562 (2004).

[34] Michael F. Modest. Radiative heat transfer. The Pennsylvania State University, 822 p. (2003).

[35] Iljushin A. A. Continuum mechanics. Moscow. Publ. Mosc. University, 287 p. (1978), (in Russian).

[36] Berezovskyj A. Nonlinear boundary value problems of a heat-radiating solids. Kyiv, Naukova Dumka, 176 p. (1968), (in Russian).

[37] Kushnir R., Protsyuk B. A Method of the Green's Functions for Quasistatic Thermoelasticity Problems in Layer Themosensitive Bodies under Complex Heat Exchange. Operator Theory: Advances and Applications. 191, 143-154 (2009).

[38] Mamedov Ya. D., Ashyrov S. A. Nonlinear Volterra equations. Ashgabat, Ylym, 176 p. (1977), (in Russian).

[39] Thermal engineering reference book. Under. Ed. V. N. Yurneva and others. Moscow, Energija. Vol.1, 744 p. (1975), (in Russian).

[40] Radiative properties of solid materials: Reference Book. Ed. A. E. Sheydlin. Moscow, Energija, 471 p. (1974), (in Russian).

[41] Machine-building materials. Quick reference. Under. Ed. V. M. Raskatova. Moscow, Mashynostrojenije, Vol.1, 511 p. (1980), (in Russian).

[42] Volkov E. A. Numerical methods. Moscow, Nauka, 256 p. (1982), (in Russian).

[43] Samarskyj A. A. Theory of difference schemes. Moscow, Nauka, 616 p. (1989), (in Russian).

[44] Bellman R., Kalaba R. Quasilinearization and nonlinear boundary value problems. Moscow, Mir, $223 \mathrm{p}$. (1968), (in Russian). 


\title{
Формулювання і розроблення методів розв'язку задач термомеханіки шаруватих опромінюваних тіл
}

\author{
Гачкевич О., Терлецький Р., Турій О. \\ Інститут прикладних проблем механіки і математики ім. Я. С. Підстригача НАН Украӥни \\ вул. Наукова, Зб, 79060, Лъвів, Україна
}

\begin{abstract}
Запропоновано математичну модель, що описує на основі феноменологічної теорії випромінювання та теорії квазістатичної термопружності термонапружений стан опромінюваних плоско-шаруватих тіл (пластин) зі складниками різної прозорості з урахуванням впливу теплового випромінювання на поверхнях, у частково прозорих областях і на межах контакту. Записано вихідні співвідношення моделі для нескінченних двошарових пластин за різних комбінацій радіаційних властивостей складників. Запропоновано методи розв'язку нових нелінійних задач. Виявлено, на основі аналізу знайдених розв'язків, ряд нових закономірностей у розподілах температури та компонент тензора напружень в опромінюваних шаруватих пластинах залежно від умов закріплення, радіаційних властивостей складників.
\end{abstract}

Ключові слова: моделювання, термонапружений стан, теплове опромінення, теплоперенос, багатошарові пластини, частково-прозорі та непрозорі шари.

2000 MSC: $74 \mathrm{~A} 15,74 \mathrm{G} 15$

УдК: 539.3 